\title{
Object recognition contributions to figure-ground organization: Operations on outlines and subjective contours
}

\author{
MARY A. PETERSON \\ University of Arizona, Tucson, Arizona \\ and \\ BRADLEY S. GIBSON \\ University of Notre Dame, Notre Dame, Indiana
}

\begin{abstract}
In previous research, replicated here, we found that some object recognition processes influence figure-ground organization. We have proposed that these object recognition processes operate on edges (or contours) detected early in visual processing, rather than on regions. Consistent with this proposal, influences from object recognition on figure-ground organization were previously observed in both pictures and stereograms depicting regions of different luminance, but not in randomdot stereograms, where edges arise late in processing (Peterson \& Gibson, 1993). In the present experiments, we examined whether or not two other types of contours-outlines and subjective contours-enable object recognition influences on figure-ground organization. For both types of contours we observed a pattern of effects similar to that originally obtained with luminance edges. The results of these experiments are valuable for distinguishing between alternative views of the mechanisms mediating object recognition influences on figure-ground organization. In addition, in both Experiments 1 and 2, fixated regions were seen as figure longer than nonfixated regions, suggesting that fixation location must be included among the variables relevant to figure-ground organization.
\end{abstract}

Since the early 20 th century, most theories of visual perception and object recognition have been grounded on the assumption that figure-ground organization and/or depth segregation must occur before object recognition (e.g., Hebb, 1949; Kosslyn, 1987; Marr, 1982; Rock, 1962, 1975; Wallach, 1949). This assumption has been embraced for various reasons. One reason is the preference for the view that early visual processes (such as figure-ground organization) must depend only on variables that can be computed from the current stimulus array and must precede any contributions from memory (such as those embodied by object recognition processes). Another reason is the belief that object recognition would be computationally impossible unless some prior processes reduced the magnitude of the problem. One candidate process has been figure-ground organization, which,

This research was supported by National Science Foundation Grant BNS-9009100 to M.A.P. and by the Air Force Office of Scientific Research. B.S.G.'s participation in writing this article was supported by a postdoctoral fellowship from NIMH (T32-MH18215) to Johns Hopkins University. Thanks to Peter Schnittman for conducting these experiments and to Philip Kellman and two anonymous reviewers for their comments on a previous version of this article. Hollis Weidenbacher and Erin Harvey contributed to a previous version of Experiment 1 , which did not include an orientation manipulation. Correspondence concerning this paper should be sent to M. A. Peterson, Department of Psychology, University of Arizona, Tucson, AZ 85721 (e-mail: mapeters@ccit.arizona.edu). on the basis of Rubin's work, has been thought to differentiate between shaped and shapeless regions in the visual field. According to Rubin (1915/1958),

when two fields have a common border, and one is seen as figure and the other as ground, the immediate perceptual experience is characterized by a shaping effect which emerges from the common border of the fields and which operates on only one field, or operates more strongly on one field than on the other.

The field which is most affected by this shaping process is figure; the other field is ground. (pp. 194-195)

Theorists writing after Rubin (e.g., Gottschaldt, 1929; Rock, 1962; Wallach, 1949) reasoned that figure-ground organization provides the shaped substrates for recognition processes and therefore must precede object (or shape) recognition. More recently, depth segregation has been accorded the role of grouping together those contours that belong together for purposes of recognition (Nakayama, Shimojo, \& Silverman, 1989).

Despite these theoretical reasons for accepting the assumption that figure ground organization precedes memory access, empirical reports suggesting that memory may influence figure-ground organization have appeared intermittently (e.g., Rubin, 1915/1958; Schafer \& Murphy, 1943). For example, in his classic research, Rubin found some tendency for figure-ground stimuli to be organized similarly on first and second viewings. reflecting a memory influence on figure-ground organi- 


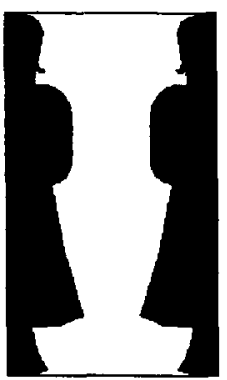

a

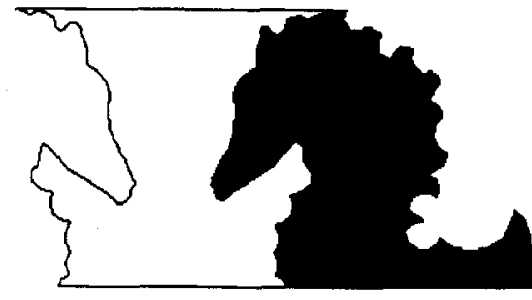

b

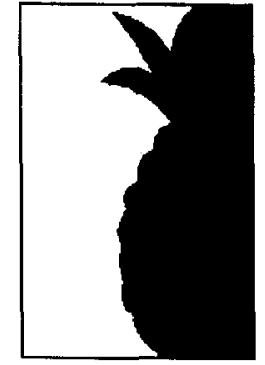

c

Figure 1. Examples of stimuli used in previous experiments examining the role of shape recognition processes in figure-ground organization. In each of these stimuli, as shown, the black region can be recognized as depicting part of an object. The center/surround stimulus in Figure 1a was used in "Shape Recognition Contributions to Figure-Ground Reversal: Which Route Counts?" by M. A. Peterson, E. M. Harvey, and H. J. Weidenbacher, 1991, Journal of Experimental Psychology: Human Perception $\&$ Performance, 17, p. 1075-1089, Figure 2A. (Copyright 1991 by the American Psychological Association. Adapted by permission). The black regions depict standing women shown from head to toe. The figure-ground stimulus in Figure $1 \mathrm{~b}$ is constructed from two bounded convex regions used in "Must Figure-Ground Organization Precede Shape Recognition? An Assumption in Peril," by M. A. Peterson and B. S. Gibson, in press, Psychological Science. (Copyright 1994 by Cambridge University Press. Adapted by permission.) The black region depicts a seahorse. In Figure 1c, the central contour carries shape recognition information; the black region depicts a pineapple. From "Shape Recognition Contributions to Figure-Ground Organization in Three-Dimensional Displays," by M. A. Peterson and B. S. Gibson, 1993, Cognitive Psychology, 25, p. 383-429, Figure 2E. (Copyright 1993 by Academic Press. Adapted by permission.)

zation. Rubin's findings, and those of most of the other investigators whose work challenged the figure-ground first assumption, were based on manipulations of laboratoryinduced familiarity. Later, other investigators who also manipulated laboratory-induced familiarity failed to replicate these earlier findings (e.g., Cornwell, 1964; Dutton \& Traill, 1933; Gottschaldt, 1929; Rock \& Fleck, 1950; Rock \& Kremen, 1957; D. Smith \& Hochberg, 1954). Consequently, the figure-ground first assumption was retained, partly because the evidence against it was unreliable.

Recently, we have found persuasive evidence that some object (or shape ${ }^{1}$ ) recognition processes operate before figure-ground organization. In our experiments, we have used stimuli like those shown in Figure 1, in which two regions sharing a border differed in how explicitly they depicted objects, as measured in preliminary studies in which observers listed which object(s) each region depicted. For one region, agreement was high (e.g., $>90 \%$ for the black regions in Figure 1), whereas for the other region, agreement was relatively low (e.g., $\leq 22 \%$ for the white regions in Figure 1). We refer to the regions eliciting high agreement as high denotative regions and the regions eliciting low agreement as low denotative regions (Peterson \& Gibson, 1991b, 1993; Peterson, Harvey, \& Weidenbacher, 1991). ${ }^{2}$ We have found that it is virtually impossible to create regions that fail to elicit an interpretation held in common by at least some of the observers. The critical difference between the high and low denotative regions is the extent to which observers agree about which object is depicted. Because denotivity values measure agreement in object recognition, they may provide some index of the goodness of fit to a representation in memory, with higher denotivities reflecting better fits. We expected that any shape recognition inputs to figure-ground organization would be large enough to be observed only when the fit between the stimulus and a memory representation exceeded some threshold (i.e., only for high denotative regions).

To assess whether or not shape recognition processes contribute to figure-ground organization, we presented the stimuli in both upright and inverted orientations and compared the likelihood of seeing the high and low denotative regions as figure in the two orientations. The high denotative regions depicted objects with a vertical axis of elongation or symmetry and with a clearly defined "top" and "bottom"-in other words, objects that had a canonical upright. It is well documented that inverting pictures of objects that have a canonical upright increases the time required for recognition (or precludes recognition), presumably because the memory representations designate a specifically oriented shape, and that a time-consuming transformation must be applied before disoriented shapes can be matched to those representations (Jolicoeur, 1985, 1988; Rock \& DiVita, 1987; Tarr \& Pinker, 1989). Our choice of the orientation manipulation depended on the time-consuming nature of the transformation process required before canonical orientation representations in memory are accessed: We reasoned that if the transformation process is not finished before figure-ground relationships are determined, inputs to figure-ground organization signaling the goodness of fit between the high denotative regions and their best-fitting representations in shape memory might be present for upright stimuli but absent for inverted stimuli. The orientation manipulation changes 
only the goodness of the initial match between the high denotative regions and their best-fitting representations in shape memory; it leaves unchanged all configural or stimulus-based inputs to figure-ground organization. ${ }^{3}$ (See Hochberg, 1968, for a similar manipulation.) Therefore, as support for the hypothesis that shape recognition processes contribute to figure-ground organization, we looked for evidence that high denotative regions were more likely to be seen as figure when the stimuli were upright rather than inverted.

Using such stimuli in experiments on figure-ground reversal, we have found that high denotative regions are maintained as figure longer when stimuli like those shown in Figure 1 are upright rather than inverted. In addition, we have found that the latency to obtain high denotative regions as figure (by reversal out of seeing the low denotative regions as figure) is shorter when the stimuli are upright rather than inverted (Peterson et al., 1991). The fact that high denotative regions were obtained as figure faster when the stimuli were upright rather than inverted implies that shape recognition processes are operating before figure-ground reversal and are contributing to the likelihood of reversal.

We have extended these findings originally obtained in a reversal paradigm to initial organization (Gibson \& Peterson, 1994; Peterson \& Gibson, 1991b, 1993, in press). Therefore, we take them to be relevant to figure-ground organization in general, rather than to figure-ground reversal in particular. Furthermore, we have extended these findings, originally obtained with two-dimensional (2-D) displays, to three-dimensional (3-D) displays, employing stimuli in which shape recognition processes either cooperated or conflicted with binocular disparity. In those experiments, we found that shape recognition contributions to the perceived depth organization of 3-D displays appeared to be as powerful as binocular disparity signals (Peterson \& Gibson, 1993). Therefore, we take our findings to be relevant to the perception of relative depth in general and not just to figure-ground organization of 2-D displays.

Once it has been demonstrated that shape recognition processes can influence perceived figure-ground organization, questions arise about how shape recognition processes can operate before figure-ground organization provides shaped regions to serve as their substrate. We have interpreted our results as reflecting shape recognition processes that operate on edges rather than on shaped regions (Peterson, 1994; Peterson \& Gibson, 1993; Peterson et al., 1991). Specifically, we have proposed that contour-parsing mechanisms operate along both sides of edges detected early in processing to delineate the parts along both sides of the contours. These parts then access representations of objects in memory, indexing in parallel those representations that best fit the two sides of the contour. Some goodness of fit index from these representations is then relayed to figure-ground computations. Thus, the outputs of these representations can exert an influence on figure-ground computations, along with the outputs of processes assessing depth cues and configurational cues. We refer to the shape recognition processes that operate prior to the completion of figure-ground computations as prefigural recognition processes. ${ }^{4}$

The notion of edge based recognition is not new (see, e.g., Barrow \& Tennenbaum, 1981; Biederman, 1987; Clowes, 1971; Hoffman \& Richards, 1985; Lowe, 1985; Marr \& Nishihara, 1978). However, most previous theoreticians within the edge-based recognition tradition have retained the figure-ground first assumption (but see Lowe, 1985). Our account is unique in permitting object recognition processes to operate on edges per se and not necessarily on the edges of regions already determined to be figures, or already emerging as figures. This difference distinguishes our proposal from other proposals regarding feedforward and feedback processes as well (e.g., McClelland \& Rumelhart, 1981), because in those accounts, shape recognition processes operate after one region begins to emerge as figure. Our account is unique in proposing a substrate for shape recognition processes (i.e., edges detected early in processing) that permits them to be initiated as early in processing as those processes that analyze other variables relevant to figure-ground organization (e.g., depth cues and configural cues).

Thus, the essential difference between our theory and other theories is our proposal that prefigural recognition processes operate on both sides of edges that are detected early in visual processing. Accordingly, it is important to characterize which types of edges support the operation of prefigural recognition processes, especially if, in doing so, we can obtain evidence consistent with our explanation of our results, and not with other explanations. That was the goal of the experiments reported here.

\section{EXPERIMENT 1}

To date, all of the experiments indicating orientationdependent shape recognition influences on figure-ground organization have employed stimuli in which a luminance edge separated contiguous black and white regions (see Figure 1). In Experiment 1, we tested whether similar effects could be observed when the contours separating potential figure and ground regions were simply thin black lines drawn on a white ground, as shown in Figure $2 b$. Even though the black line in the center of Figure $2 \mathrm{~b}$ demarcates two regions that are identical in luminance, the outline itself constitutes a luminance edge. Therefore, it should be detected early in visual processing, as luminance edges separating regions of different lightness are (Hochberg, 1978; Marr \& Hildreth, 1980), and should, therefore, be a suitable surrogate for a luminance edge (Halverson, 1992; Hochberg, 1972; Kennedy \& Silver, 1974). Hence, if the critical property of the edges used in previous work is that they were detected early in processing (and not some other property that distinguishes them from outline drawings), then a similar pattern of results should be obtained with outline drawings. 


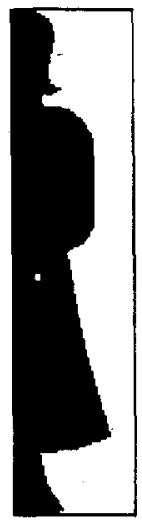

a

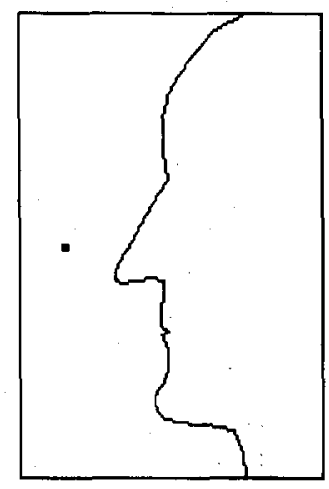

b

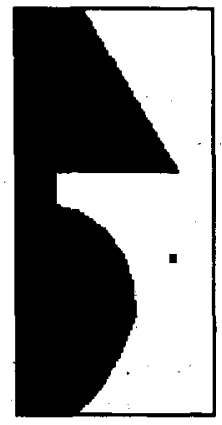

C
Figure 2. The figure-ground stimuli used in Experiment 1. Figure 2a is a luminance edge stimulus in which the high denotative region (the region in black) depicts a standing woman. Figure $2 \mathrm{~b}$ is an outline drawing in which the high denotative region (the region on the right) depicts a profile of a face. Figure $2 \mathrm{c}$ is a luminance edge version of the practice stimulus. The high denotative region (in black) depicts a lamp. (Figure 2A is from "Shape Recognition Contributions to Figure-Ground Organization in Three-Dimensional Displays," by M. A. Peterson and B. S. Gibson, 1993, Cognitive Psychology, 25, p. 383-429, Figure 2D. Copyright 1993 by Academic Press. Adapted by permission. Figure $2 \mathrm{C}$ is from the article "Does OrientationIndependent Object Recognition Precede Orientation-Dependent Recognition? Evidence From a Cuing Paradigm," by B. S. Gibson and M. A. Peterson, 1994, Journal of Experimental Psychology: Human Perception \& Performance, 20, p. 299-316, Figure 2C. Copyright 1994 by the American Psychological Association. Adapted by permission.)

Outline drawings have been used as surrogates for objects in much contemporary research on object recognition (e.g., Biederman, 1987; Jolicoeur, 1985, 1988). In figure-ground reversal paradigms, similar reversal patterns have been found for outline drawings and for black and white stimuli (e.g., Jenkins \& Ross, 1977). Therefore, one might expect that for our task, performance with outline drawings would be similar to performance with black and white stimuli. However, none of the previous studies of figure-ground reversal involved manipulations of orientation or of the denotivity of the regions on the two sides of the border. Hence, it is unclear whether or not the specific pattern of reversals that we take to reveal the operation of prefigural recognition processes will be obtained with outline drawings (e.g., longer durations of maintaining high denotative regions as figure and shorter latencies to obtain high denotative regions as figure when the stimuli are upright rather than inverted). A finding that performance with outline drawings is similar to performance with black and white stimuli would be consistent with our proposal that these results reflect contributions from shape recognition processes operating on both sides of the edges that are detected early in visual processing.

\section{Method}

Subjects. The subjects were 31 students at the University of Arizona who participated in this experiment in partial fulfillment of the requirements for their int roductory psychology course. All reported vision that was normal or was corrected to normal.

Stimuli and Apparatus. The experimental stimuli were the two stimuli shown in Figures $2 \mathrm{a}$ and $2 \mathrm{~b}$, depicting two regions separated by a central border and contained within a rectangular border. The central border was the figure-ground border of interest in this experiment. ${ }^{5}$ Figure $2 \mathrm{c}$ was used as a practice stimulus. Figure $2 \mathrm{a}$ was used by Peterson and Gibson (1993), and Figures $2 \mathrm{~b}$ and $2 \mathrm{c}$ were drawn from a set of similar figures developed by Peterson and her colleagues. For all of these stimuli, the two regions on either side of the central border were approximately equal in area and convexity. The regions were designed to be unequal in denotivity: In a preliminary study, $100 \%$ of the observers had agreed on a single interpretation for the high denotative regions of Figures $2 \mathrm{a}$ and $2 \mathrm{~b}$, whereas less than $17 \%$ had agreed on an interpretation for the low denotative regions of these stimuli.

Both outline drawings and black and white versions of the stimuli were created. In the black and white version, the region on one side of the central border was black and the region on the other side was white, as shown in Figures $2 \mathrm{a}$ and $2 \mathrm{c}$. The black and white stimuli were displayed against a medium gray background. In the outline drawing version, a thin black contour (4' of arc of visual angle) was used to delineate both the outer frame and the border between the two regions of the figure-ground stimulus; both regions of the figure-ground stimuli were white, as shown in Figure $2 b$, as was the background against which the luminance contour stimuli were displayed.

Small rectangles located on one of the potential figural regions on either side of the figure-ground border served as fixation "points." The fixation points $\left(4^{\prime} \times 5^{\prime}\right.$ of arc of visual angle) were roughly centered on the regions on either side of the central contour. The fixation points were located approximately $20^{\prime}$ of arc from the central border of Figure $2 a$; those on Figure $2 b$ were located approximately $33^{\prime}$ of arc from the central border. The fixation points contrasted with the lightness of the region on which they lay: Fixation points on white regions were black, and fixation points on black regions were white. For both the outline drawings and the black and white stimuli, we created one version containing a fixation point on the region on the left of the central border, and one version containing a fixation point on the region on the right of the central border (see Figure 2). ${ }^{6}$

All stimuli were displayed on a monitor located $105 \mathrm{~cm}$ from the observers. At this distance, Figure 2a subtended approximately $5.1^{\circ} \times 1.0^{\circ}$ of visual angle in height and width, respectively; Figure $2 \mathrm{~b}$ subtended approximately $4.4^{\circ} \times 2.4^{\circ}$; and Figure $2 \mathrm{c}$ subtended approximately $4.3^{\circ} \times 1.7^{\circ}$. Observers indicated which region they saw as figure by pressing one of two keys on a keyboard. They pressed a key located on the right side of the keyboard when the region to the right of the central border appeared to be figure, and they pressed a key located on the left side of the keyboard when the region to the left of the central border appeared to be figure. A Compaq 286 computer fitted with a Metrabyte I/O card was used to display the stimuli and record responses.

Procedure. The subjects were first shown a black and white version of the Rubin vase/faces picture and introduced to the general principles of figure-ground organization. They were told that the region seen as figure (1) appeared to have a definite shape, whereas the other region did not, and (2) would appear to be in front of the ground region (the ground would appear to continue behind the figure). The subjects then viewed a black and white version of Figure $2 \mathrm{c}$ and observed that figure-ground reversals with the same properties occurred for this stimulus as well.

The subjects were told that they would be viewing figure-ground stimuli with regions to the right and left of a central border throughout the experiment and would be reporting about what they perceived by pressing a key on the right side of the computer keyboard whenever the region on the right of the central figure-ground border appeared to be figure (and keeping it depressed for as long 
as the region on the right of the central contour appeared to be figure) and pressing a key on the left of the keyboard when the region on the left appeared to be as figure. The subjects were told that they would view these stimuli under instructions to try to see either the right or the left side of the stimulus as figure. These instructions were printed on the computer screen before each trial. The subjects were instructed to follow these "intention" instructions by concentrating only, and not by moving their eyes from the fixation point. The experimenter stressed that the fixation task was the primary task in the experiment and was not to be abandoned in order to follow the intention instructions. The subjects were instructed to report seeing a region as figure only when it satisfied the joint figure-ground criteria listed above. They were instructed to remove their fingers from both keys if they ever saw both regions as figure, or if the display appeared flat so that neither the high nor the low denotative region appeared to be in front of the other. ${ }^{7}$

This general procedure is the opposed-set procedure, introduced by Peterson and Hochberg (1983). In this procedure, intention instructions are used to place upper and lower limits on any intentions that observers might have to try to see one region as figure. Using this opposed-set procedure, Peterson and Hochberg (1983, 1989; Hochberg \& Peterson, 1987; Peterson, 1986; Peterson \& Gibson, 1991a, 1993; Peterson et al., 1991) have shown that observers' intentions can influence how reversible figures are perceived. They have used a number of methods to show that responses in this paradigm are largely free of response bias. For instance, Hochberg and Peterson (1987, 1993; Peterson, 1986) measured perceived organization both directly, by recording responses about the variable to which the intention instructions referred (typically depth organization), and indirectly, by recording responses about variables "perceptually coupled" with those to which the intention instructions referred (typically direction of movement reports). Observers are not likely to be aware of the coupling between perceptual variables. Therefore, any demand character induced by the intention instructions referring to depth organization was not expected to contribute to responses about direction of movement. Both direct and indirect measures revealed strong evidence for influences of observers' intentions on perceived organization. Given these previous demonstrations that intention can influence the perceived organization of ambiguous figures, the use of the opposed-set procedure is recommended for controlling observers' intentions whenever they might be expected to influence perception. (Evidence ruling out a response bias interpretation of the results found here is reported in the present Results sections; see also the General Discussion.)

The subjects participated in four practice trials before the experimental trials. They viewed black and white stimuli on two of these practice trials and outline drawings on the other two practice trials. They practiced with one upright and one inverted stimulus of each stimulus type, and with one stimulus in which the fixation point was located inside the region to which the intention instructions referred and one stimulus in which the fixation point was located outside the region to which the intention instructions referred. After each practice trial, the subjects were questioned about their ability to maintain fixation, to concentrate on following the intention instructions throughout the trial, and to report all reversals that they saw. The importance of these instructions and, in particular, of the fixation instructions was reiterated after each practice trial.

Following the practice trials, the subjects were shown the experimental stimuli, and the high denotative regions were pointed out to them. Next, they participated in 32 experimental trials, each lasting $30 \mathrm{sec}$. The experiment was self-paced, except for two mandatory breaks, one after trial number 12 , and one after trial number 24 . For half the subjects, the high denotative region of Figure 2a was located on the left of the central border and the high denotative region of Figure $2 b$ was located on the right; for the other half, the locations of these high denotative regions were reversed. For a given subject, the right/left location of the high denotative region was maintained across the black and white and the outline drawing versions. For each subject, for the black and white stimuli, one high denotative region was white; the other was black. For half the subjects, the high denotative region of Figure $2 \mathrm{a}$ was black and the high denotative region of Figure $2 b$ was white; for the other half, the lightness of the high and low denotative regions of Figures $2 \mathrm{a}$ and $2 \mathrm{~b}$ were reversed. Between subjects, the lightness of the high denotative regions was crossed with location. The subjects viewed the stimuli in eight blocks of four trials, with each block consisting of one stimulus type in one orientation. The four trials per block included two trials on which subjects were asked to try to see the high denotative region as figure and two trials on which they were asked to try to see the low denotative region as figure. Each intention instruction occurred once per block with fixation inside the region to which the intention instructions referred and once with fixation outside the region to which the intention instructions referred. The intention instructions alternated in an $\mathrm{ABAB}$ pattern within these blocks, and the fixation location alternated in an ABBA pattern. The order of these blocks differed across subjects in a Latin square design. Half the subjects started with an instruction to try to see the right side as figure (the other half with the instruction to try to see the left side as figure); half the subjects began by viewing a black and white stimulus (the other half began by viewing an outline drawing stimulus); half began by viewing an upright stimulus (the other half by viewing an inverted stimulus).

Data analysis. Figure 3 is a schematic intended to make the data analysis clear. For each $30-\mathrm{sec}$ trial, we summed the individual keypress durations for the right and left keys and calculated the mean durations of seeing both the right and the left regions as figure on a given trial. Referring to the intention instructions, we labeled these means as either the mean duration the intended region was maintained as figure $(I)$ or the mean duration the unintended region was maintained as figure $(U)$. Consider a trial on which observers viewed an upright stimulus and were instructed to try to see a high denotative region on the left as figure (e.g., Figure 3a). On this trial, the durations of left keypresses would be used to compute the mean duration of maintaining the high denotative region as figure when it was the intended region $\left(I_{\mathrm{HD}}\right)$ and the durations of right keypresses would be used to compute the mean duration of maintaining the low denotative region as figure when it was the unintended region $\left(U_{\mathrm{LD}}\right)$. On a trial on which observers viewed the same figure but were asked to try to see the low denotative region on the right as figure (e.g., Figure $3 b$ ), the durations of right keypresses would be used to compute the mean duration of maintaining the low denotative region as figure when it was the intended region $\left(I_{\mathrm{LD}}\right)$ and the durations of left keypresses would be used to compute the mean duration of maintaining the high denotative region as figure when it was the unintended region $\left(U_{\mathrm{HD}}\right)$. Thus, the $I$ measures for high denotative and low denotative regions were obtained on different trials. Likewise, the $I_{\mathrm{HD}}$ and $U_{\mathrm{HD}}$ measures were obtained on different trials, as were the $I_{\mathrm{LD}}$ and $U_{\mathrm{LD}}$ measures.

We were most interested in observing whether the $I$ and $U$ measures obtained for the two types of stimuli employed in this experiment would replicate those obtained previously (Peterson et al., 1991); specifically:

1. We were interested in observing whether or not intended high denotative regions were maintained as figure longer when upright rather than inverted [I(maintain)]. That is, we examined whether or not $I_{\mathrm{HD}}$ was larger for upright stimuli than for inverted stimuli by testing whether

$$
\text { [Upright } \left.I_{\mathrm{HD}}-\text { Inverted } I_{\mathrm{HD}}\right]>0 \text {. }
$$

(See Figure 3). In a supplementary analysis, we looked for similar effects in $U$ measures (e.g., whether [Upright $U_{\mathrm{HD}}$ - Inverted 

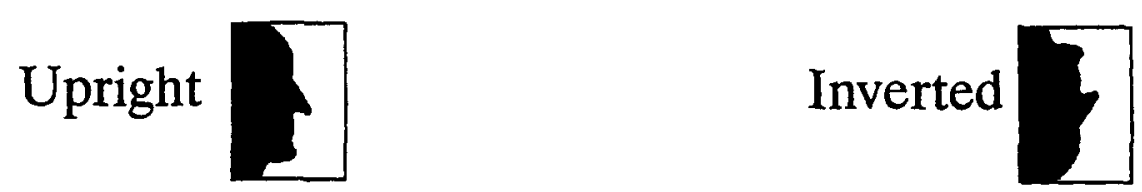

\section{HOLD INSTRUCTION}
a. Hold HD
b. Hold LD
c. Hold HD
d. Hold LD

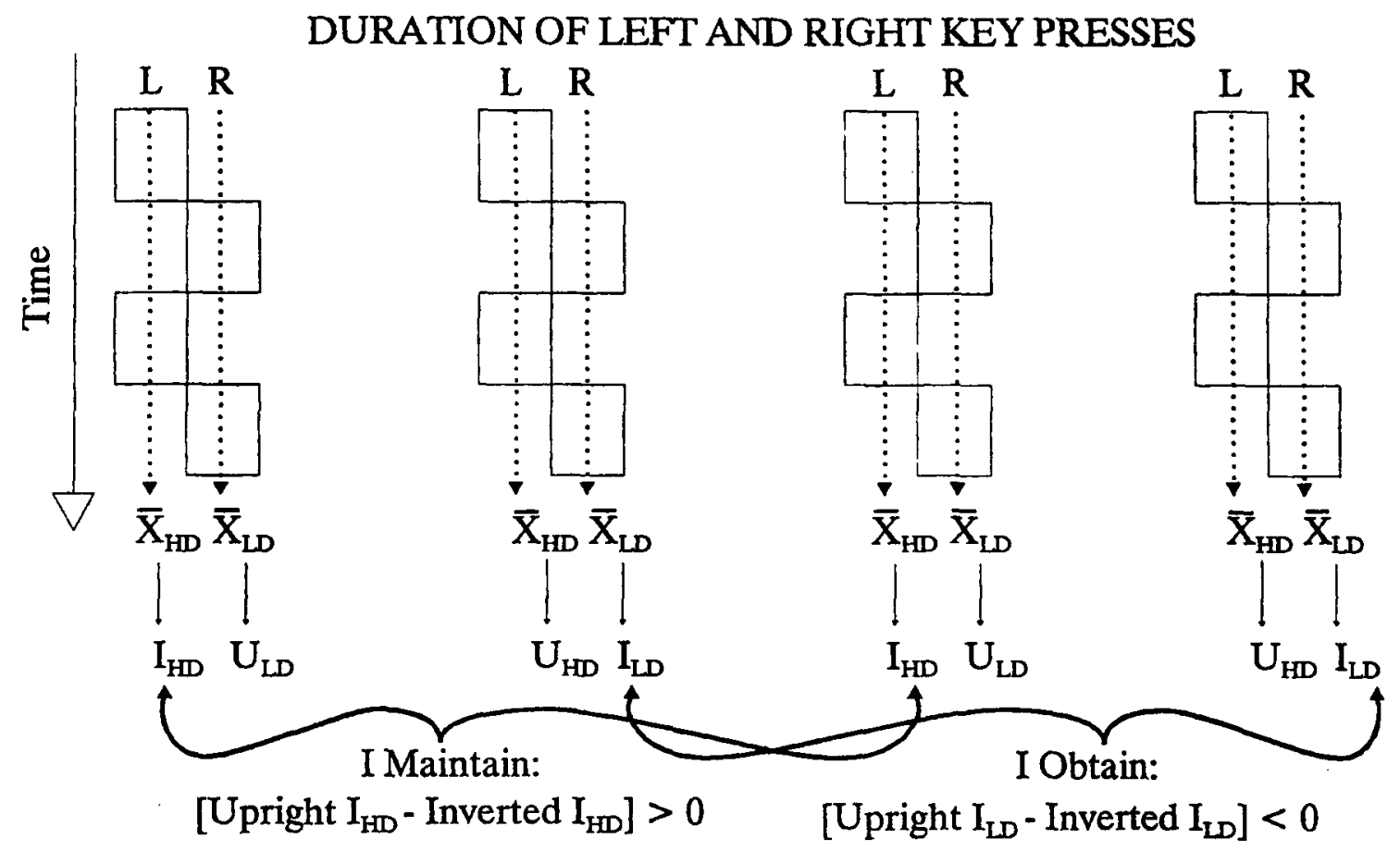

Figure 3. A schematic showing how reports of figure-ground organization obtained under different intention instructions were translated into intended $(I)$ and unintended $(U)$ measures for both upright (3a-3b) and inverted (3c-3d) stimuli. Columns labeled a, b, c, and d are different 30-sec trials under opposed hold instructions. For each trial, left and right keypresses are shown. In this figure, the high denotative (HD) region is shown on the left and the low denotative (LD) region is shown on the right. Average duration of pressing the left and the right keys are calculated for each trial and are labeled according to the intention instructions as measures of intended $(I)$ or unintended $(U)$ durations. Figure 3 also shows the comparisons that indicated $(1)$ whether the intended high denotative region is maintained as figure longer for upright rather than inverted stimuli [I(maintain); a similar contrast was calculated for the unintended high denotative durations], and (2) whether the latency to obtain the high denotative region as figure by reversal out of seeing the low denotative region as figure was shorter for upright rather than imverted stimuli [I(obtain); a similar contrast was calculated for the unintended low denotative durations].

$\left.U_{\mathrm{HD}}\right]>0$ ). Influences that are evident in both the $I$ and $U$ durations identify variables that contribute to figure-ground organization regardless of the viewer's intentions (see Peterson et al., 1991).

2. We were also interested in observing whether or not the latency to obtain high denotative regions by reversal out of seeing the intended low denotative regions as figure was shorter when the stimuli were upright rather than inverted [I(obtain)]. The latency to obtain the high denotative region as figure is measured by observing the durations of seeing the (intended) low denotative region as figure; shorter durations of seeing the low denotative region as figure indicate shorter latencies before reversal into seeing the high denotative region as figure. For this contrast, we examined whether $I$ measures for low denotative regions were smaller for upright stimuli than for inverted stimuli by testing whether

$$
\text { [Upright } \left.I_{\mathrm{LD}}-\text { Inverted } I_{\mathrm{LD}}\right]<0 \text {. }
$$

(See Figure 3.) Notice that our index of the latency to obtain high denotative regions as figure is derived from data recorded when observers tried to see the low denotative region as figure. In a supplementary analysis, we looked for similar effects in $U$ measures for the low denotative region, as in (1).

As is clear in Figure 3, I(maintain) and $I$ (obtain) are independent; for a stimulus with a given orientation, the latency to obtain the high denotative region as figure is evident in the $I$ measures calculated from trials on which observers try to maintain the low denotative region as figure, whereas the length of maintaining the high denotative region as figure is evident in the $I$ measures calculated from trials on which observers try to maintain the high denotative region as figure.

\section{Results and Discussion}

Durations of maintaining intended regions as figure $(I)$. The orientation-dependent shape recognition ef- 


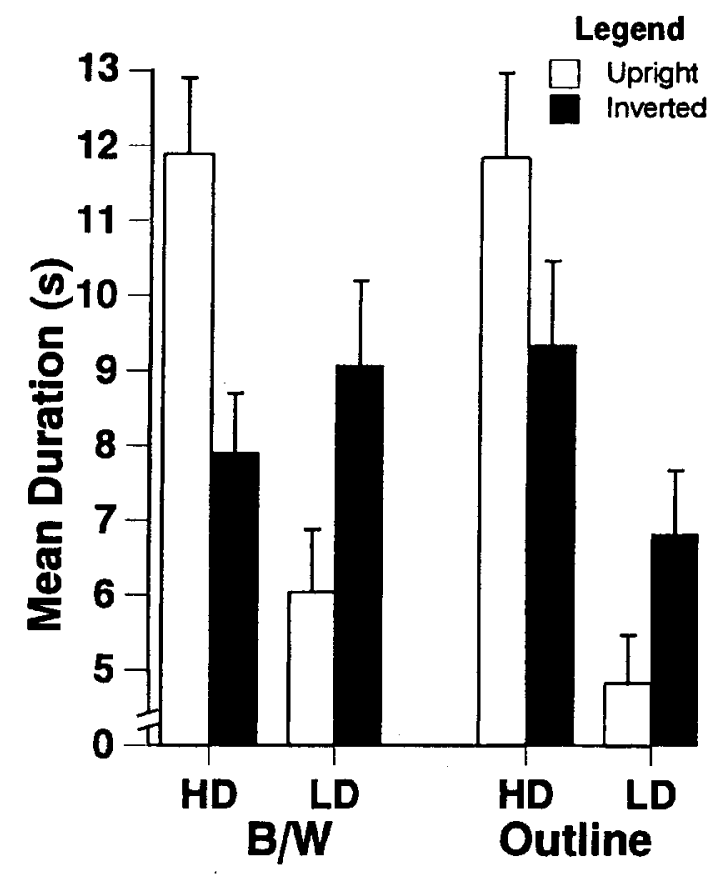

Figure 4. The mean durations of seeing intended high and low denotative regions as figure as a function of orientation for the two types of stimuli used in Experiment 1. Luminance edge stimuli (black and white, B/W, stimuli) are shown on the left, and outline stimuli on the right. HD, high denotative region; $L D$, low denotative region. The upright condition is represented by white bars; the inverted condition, by black bars.

fects were the same for outline drawings and for black and white stimuli. The main effect of stimulus type failed to reach significance $(p>.24)$. Nevertheless, we present the data from the two types of stimuli separately in Figure 4.

Shape recognition influences on figure-ground organization were evident for both types of stimuli. Intended high denotative regions were maintained as figure for longer durations when the stimuli were upright rather than inverted for both black and white stimuli and for outline drawings. In addition, intended low denotative regions were seen as figure for shorter durations when the stimuli were upright rather than inverted, indicating that (unintended) high denotative regions were more likely to be obtained as figure by reversal out of seeing the low denotative region as figure in the upright condition than in the inverted condition. Again, the pattern of effects was similar for both black and white stimuli and outline drawings. An analysis of variance (ANOVA) conducted on the $I$ measures revealed a main effect of denotivity $[F(1,30)=24.87, p<.0001]$ and a significant interaction between orientation and denotivity $[F(1,30)=$ $42.81, p<.0001]$. For both low denotative and high denotative regions, the upright versus inverted comparisons were significant at levels of $p<.01$ or better. These results replicate those reported by Peterson et al. (1991).

Even though the main effect of stimulus type was not significant, the two-way interaction between stimulus type and denotivity was significant $[F(1,30)=7.78, p<$ $.01]$ : For both upright and inverted stimuli, intended low denotative regions were maintained as figure for longer durations in black and white stimuli rather than in outline drawings, whereas intended high denotative regions were maintained as figure for approximately equal durations in both types of stimuli. This two-way interaction between denotivity and stimulus type cannot be taken to reflect the differential operation of prefigural shape recognition processes along the two types of borders, because it was not orientation-dependent: The three-way interaction among orientation, denotivity, and border type failed to reach significance $(p>.16)$. Prefigural shape recognition processes are implicated only when an interaction between denotivity and orientation is involved. Rather, we take the relatively shorter durations of seeing the low denotative region as figure in the outline versions to reflect an orientation-independent intentional strategy. This strategy was apparently used for the low denotative regions and not the high denotative regions and may have required greater perceptibility of the shape-defining contours than was provided by the outline contours.

Intended regions were maintained as figure longer when subjects were fixating a point located inside that region rather than a point located outside that region $[F(1,30)=15.88, p<.0005]$, as can be seen in Table 1 (rows 1-3). This finding supports Hochberg's (1971) proposal that fixated regions should be more likely than nonfixated regions to be seen as figure. An interaction between denotivity and fixation point location was obtained $[F(1,30)=6.18, p<.02]$ : The difference between maintaining fixated and nonfixated regions as figure was larger for high denotative regions than for low denotative regions. But once again, the three-way interaction among denotivity, fixation location, and orientation was not significant $(p>.25)$, which suggests that fixation location does not alter the outputs of orientation-dependent representations of shapes in memory.

Durations of seeing unintended regions as figure $(U)$. The main effects that were significant in the analysis of the intended durations were significant in an analysis of the unintended durations as well. Overall, even when observers were not trying to maintain the high denotative regions as figure, high denotative regions were seen as

Table 1

Mean Intended and Unintended Durations for High Denotative and Low Denotative Regions, as a Function of Fixation Location in Experiment 1

\begin{tabular}{lcccc}
\hline & \multicolumn{4}{c}{ Fixation } \\
\cline { 2 - 4 } Denotivity & \multicolumn{2}{c}{ Inside } & \multicolumn{2}{c}{ Outside } \\
\cline { 2 - 4 } \cline { 4 - 5 } & $M$ & $S E$ & $M$ & $S E$ \\
\hline \multirow{4}{*}{ High } & Intended Regions & Maintained & as Figure $(I)$ \\
Low & 11.05 & 0.94 & 9.01 & 0.86 \\
Mean & 7.15 & 0.91 & 6.23 & 0.75 \\
& 9.10 & 0.83 & 7.62 & 0.73 \\
High & Unintended Regions Maintained as Figure $(U)$ & \\
Low & 5.07 & 0.59 & 4.40 & 0.64 \\
Mean & 3.02 & 0.28 & 2.29 & 0.39 \\
& 4.04 & 0.35 & 3.34 & 0.46 \\
\hline
\end{tabular}


figure for longer durations than were low denotative regions $[F(1,30)=13.78, p<.001]$. In addition, unintended high denotative regions were seen as figure for longer durations in the upright rather than the inverted condition, just as they were when observers were following instructions to try to maintain them as figure. Like the $I$ measures, the $U$ measures revealed that unintended low denotative regions were seen as figure for shorter durations in the upright rather than the inverted condition, indicating a shorter latency to obtain (intended) high denotative regions as figure by reversal out of seeing unintended low denotative regions as figure when the stimuli were upright rather than inverted. The significance of this effect was shown by the two-way interaction between denotivity and orientation $[F(1,30)=$ $12.71, p<.002]$.

These orientation-dependent shape recognition effects were evident for both types of stimuli, replicating the effects obtained in the intended durations: The threeway interaction among border type, denotivity, and orientation failed to reach significance $(p>.08)$, as did the main effect of border type $(p>.09)$. The two-way interaction between denotivity and border type was not significant for the $U$ measures ( $p>.38$ ).

As can be seen in Table 1 (rows 4-6), fixated unintended regions were maintained as figure longer than nonfixated unintended regions $[F(1,30)=4.95, p<.04]$. No interactions involving fixation location were significant (all $p \mathrm{~s}>.10$ ).

Thus, analyses of the $U$ measures revealed both orientation-dependent shape recognition effects and fixation location effects; effects that were evident in the $I$ measure as well. Effects of variables that contribute to figure-ground organization regardless of the viewer's intentions should be evident in both the $I$ and $U$ measures (see Peterson et al., 1991). The replication of results across both $I$ and $U$ measures also serves as evidence against a response bias explanation of our results. Additional evidence against a response bias interpretation is that the shape recognition influences were evident for upright stimuli and not for inverted stimuli. Observers knew that the object depicted by the high denotative region was simply inverted in the one condition relative to the other. Therefore, any motivational factors that did not depend on access to representations specifying the canonical orientation of the depicted object should have been unaffected by changes in orientation (Peterson et al., 1991).

In addition to the main finding that outline drawings and black and white stimuli serve as comparable substrates for prefigural recognition processes, the results of Experiment 1 provide empirical support for the role of fixation location in figure-ground organization. In our previous experiments with stimuli like those shown in Figure 1, the fixation point was located on the figureground border so that neither region was favored by fixation location, or it was located on the low denotative region. In the present experiment, we tested a prediction made by Hochberg (1971) that fixation location might influence figure-ground organization. Hochberg thought that fixation location might mediate effects of prior experience on figure-ground organization via learned perceptual expectancies, inasmuch as figures are most often fixated and backgrounds most often nonfixated (and therefore unfocused). We found that fixation location did indeed influence figure-ground organization, although its effects were similar for both high denotative regions and low denotative regions. Thus, although fixation location is clearly relevant to figure-ground organization, it does not mediate all effects of prior experience on figure-ground organization. Recently, Sejnowski and Hinton (1987) used spatial attention location in a parallel relaxation model as a "seed" to bias the figure-ground computation. The effects of fixation location obtained in our experiment may be mediated by spatial attention location; our design does not allow us to separate spatial attention location from fixation location (but see Peterson \& Gibson, 1991a). Like other variables relevant to figure-ground organization, fixation location is not the sole determinant of figure-ground organization. Indeed, as pointed out by Rubin (1915/1958), one can fixate and/or attend to the ground, and it can nevertheless remain the ground.

The major finding of Experiment 1 for the purposes of this paper was that similar effects were obtained with outline drawings and with black and white stimuli: For both black and white stimuli and outline drawings, high denotative regions were obtained as figure faster and maintained as figure longer when the stimuli were upright rather than inverted. Thus, Experiment 1 replicates and extends our previous findings, and identifies another type of contour that supports the operation of prefigural recognition processes.

\section{EXPERIMENT 2}

In Experiment 2, we extended our inquiry to stimuli in which a high denotative region is separated from a low denotative region by a contour that is not physically present - an illusory or subjective contour (Kanizsa, 1976; Schumann, 1987), like that shown in Figure 5a. Subjective contour stimuli are an interesting case because Rock (1983) claimed that subjective contours are perceived in order to account for what would otherwise be "coincidental regularities" in an initial unconscious figure-ground organization (pp. 140-141). Evidence suggesting that it takes time and/or attention to see subjective contours has been taken to be consistent with this view (Reynolds, 1981; Rock \& Anson, 1979). If subjective contours are generated only after figure-ground relationships have been determined unconsciously, they may arise too late in processing to support the operation of prefigural recognition processes.

A different prediction can be generated on the basis of recent physiological and psychophysical evidence suggesting that subjective contours are constructed very early in visual processing, however. For example, von der Heydt and Peterhans (1989; Peterhans \& von der 


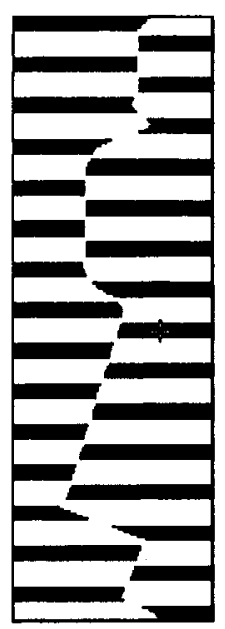

a

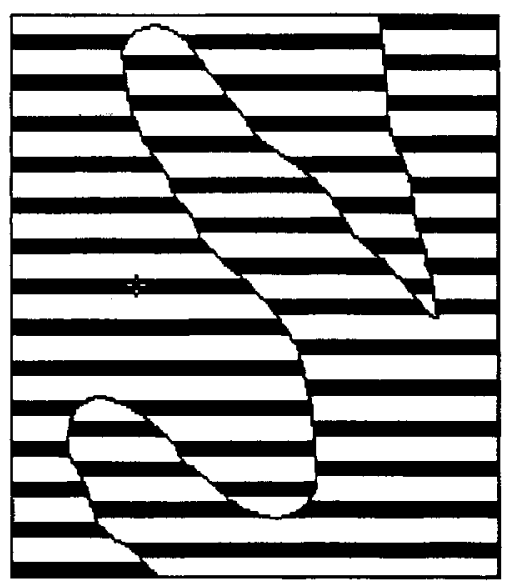

b

Figure 5. The figure-ground stimuli used in Experiment 2. Figure 5a is a subjective contour version of Figure $2 \mathrm{a}$. Figure $5 \mathrm{~b}$ is an outline version of the practice stimulus. The high denotative region of Figure $5 b$ (the region on the right) depicts part of $a$ hand.

Heydt, 1989; von der Heydt, Peterhans, \& Baumgartner, 1984) found that a substantial proportion of cells in monkey $\mathrm{V} 2$ responded with short latencies to subjective contours as well as to real contours. In addition, behavioral evidence suggests that subjective contours produce some of the same consequences as real contours do-for example, tilt aftereffects (Paradiso, Shimojo, \& Nakayama, 1989; Smith \& Over, 1975); the Zöllner illusion (Pastore, 1971); and parallel visual search functions (Gurnsey, Humphrey, \& Kapitan, 1992). (See also theoretical proposals by Grossberg \& Mingolla, 1985.) On the basis of the latter evidence, we reasoned that subjective contours might be identified early enough in visual processing to support the operation of prefigural shape recognition processes, and hence, to produce orientationdependent shape recognition effects on figure-ground reversal equivalent to those obtained with real contours.

In Experiment 2, we showed observers stimuli in which the central border between the high and low denotative regions was either a subjective contour or an outline contour. Subjective contours were induced by offset gratings (Ehrenstein, 1987; Varin, 1971, cited in Kanizsa, 1979). An illustration is shown in Figure 5a. In offset grating figures, the mean luminance of the horizontal inducing bars is the same on either side of the subjective contour. Hence, the use of this induction method ensures that the putatively subjective contour is not a luminance edge, as some types of subjective contours have been shown to be (Ginsburg, 1975). Real contour versions of the stimuli were created by filling in an outline contour between the inducing elements, as shown in Figure $5 \mathrm{~b}$.

We assessed the effects of fixation location again in this experiment both because a new empirical finding deserves replication, and because fixation effects ob- tained for regions delimited by real contours might not extend to regions delimited by subjective contours.

\section{Method}

Subjects. The subjects were 32 students at the University of Arizona who participated in this experiment in partial fulfillment of the requirements for their introductory psychology course. All reported having vision that was normal or was corrected to normal.

Stimuli and Apparatus. The stimuli used are shown in Figure 5. Figure 5a shows a subjective contour version of Figure $2 a$, created from offset gratings; this was our experimental stimulus. The width of the bars in the offset gratings was approximately $9.6^{\prime}$ of visual angle. The bars on alternate sides of the subjective contour were separated by $3.2^{\prime}$ of visual angle, and the bars on the same side of the contour were separated by $17^{\prime}$ of visual angle. Following Petry, Harbeck, Conway, and Levey (1983), we chose these separation values in order to maximize the sharpness of the subjective contour. (However, the sharpness of subjective contours induced along diagonal line endings may have been weakened slightly, owing to limitations in the resolution of our monitor; see Kennedy, 1988.) Real contour versions of the stimuli were created by filling in a contour $4^{\prime}$ of arc wide in the location of the subjective contour. Figure $5 \mathrm{~b}$ shows an outline contour version of the practice stimulus used in Experiment 2 (this stimulus was a modified version of those used by Peterson \& Gibson, 1993). Upright and inverted versions of each type of figure were created. For both real and subjective contour stimuli, two bar-height versions were created: One in which the highest bar in the visual field lay on the low denotative region and the lowest bar lay on the high denotative region (see Figure 5a), and another in which these bar-height relationships were reversed (see Figure $5 b$ ). Because of its similarity to the depth cue of height in field, bar height was manipulated within subjects so that we could examine its effects on figure-ground organization. Half the subjects saw the subjective contour stimulus first, and half saw the outline drawing first.

For each of these eight stimuli, two additional versions were created. One version contained a fixation cross located within the high denotative region, and a second version contained a fixation cross located within the low denotative region. Fixation crosses 
(approximately $14^{\prime} \times 11^{\prime}$ of visual angle in height and width) were centered in the appropriate region, at a distance of approximately $30^{\prime}$ of visual angle from the center contour. When the fixation cross lay on a black stripe, it was white; when it lay on a white stripe, it was black.

The number of variables manipulated in Experiment 2 precluded our using more than one stimulus per subject. The large number of variables made the sessions long; each session lasted $1 \mathrm{~h}$, even though only one stimulus was used. In other research, we have found that observers following opposed-set fixation and intention instructions are excessively fatigued following experimental sessions lasting much longer than an hour. Moreover, it was difficult to create a number of different subjective contour stimuli by using the offset grating method (which we favored because the luminance of the regions on the two sides of the subjective contour is the same) because many of our stimuli contain a horizontal component in their contour (see Figures $2 b$ and $2 c$ ). Were we to attempt to make subjective contour versions of these stimuli by using the offset grating method, subjective contours would alternate with real contours along the central border. We did not consider such stimuli adequate to test whether or not prefigural recognition processes could operate on subjective contours; hence, the number of potential stimuli available to us was reduced. Furthermore, attempts to induce subjective contours via Pacman-like elements created local luminance differences across the contour, thereby destroying its status as a subjective contour (Ginsburg, 1975). The use of only one stimulus might be considered to be a handicap in some circumstances. We do not think that it is a disadvantage here, because we were not trying to establish an effect or to establish its generality over a number of different stimuli; we were interested simply in determining whether or not a wellestablished effect could be replicated with a subjective contour as opposed to a real contour.

The stimuli were presented on a Princeton monitor, located at a distance of $94 \mathrm{~cm}$ from the observers. At this distance, Figure 5a subtended approximately $6.7^{\circ} \times 2.0^{\circ}$ of visual angle; Figure $5 b$ subtended approximately $6.3^{\circ} \times 4.8^{\circ}$. Stimulus presentation, timing of trial duration, and response recording were controlled by a Compaq 286 microcomputer.

Procedure. The procedure was similar to the procedure used in Experiment 1, with the following exceptions. Before participating in the experiment, observers viewed both an outline drawing and a subjective contour version of a practice stimulus in which the high denotative region depicted a part of a hand, as shown in Figure 5b. The experimenter ascertained that the observers could see a contour in the subjective contour versions of the stimuli, but at no time did he refer to the stimuli as "subjective" or "real" contour stimuli. Observers participated in four practice trials before the experimental trials. The practice trials were chosen so that observers were exposed to each level of each variable equally often during practice: Across the practice trials, half the stimuli were subjective contour stimuli (the other half were outline stimuli), half were upright (the other half were inverted), half the fixation locations were inside the intended region (the other half were outside), and half the intention instructions referred to the high denotative region (the other half referred to the low denotative region). Each observer participated in 32 experimental trials. They were given breaks approximately one third and two thirds of the way through the experimental trials. Half the subjects viewed a stimulus depicting the high denotative region on the left; the other half viewed a stimulus depicting the high denotative region on the right. The order of hold instructions was counterbalanced within subjects; the order of fixation location (on or off with respect to the intended region) alternated within subjects. The order of conditions was counterbalanced across subjects in a Latin square design.

\section{Results and Discussion}

Durations of maintaining intended regions as figure (I). The orientation-dependent shape recognition effects were the same for the outline contour and the subjective contour stimuli. The main effect of stimulus type failed to reach significance $(p>.08)$. Nevertheless, in Figure 6, we present the data from the two types of figure-ground contours separately. Intended high denotative regions were maintained as figure longer in the upright rather than the inverted orientation for both outline and subjective contour versions of the stimuli. In addition, intended low denotative regions were maintained as figure for shorter durations in the upright orientation rather than the inverted orientation, indicating that the latency to obtain (unintended) high denotative regions by reversal out of seeing low denotative regions as figure was shorter in upright rather than inverted stimuli. Again, a similar pattern was obtained for outline and subjective contour versions of the stimuli. These effects were reflected in an ANOVA conducted on the $I$ measures in a main effect of denotivity $[F(1,31)=11.67$, $p<.002]$ and a significant interaction between orientation and denotivity $[F(1,31)=11.13, p<.003]$. Individual comparisons between upright and inverted durations were significant at a level of $p<.05$ or better.

As in Experiment 1, a significant two-way interaction between denotivity and stimulus type was obtained

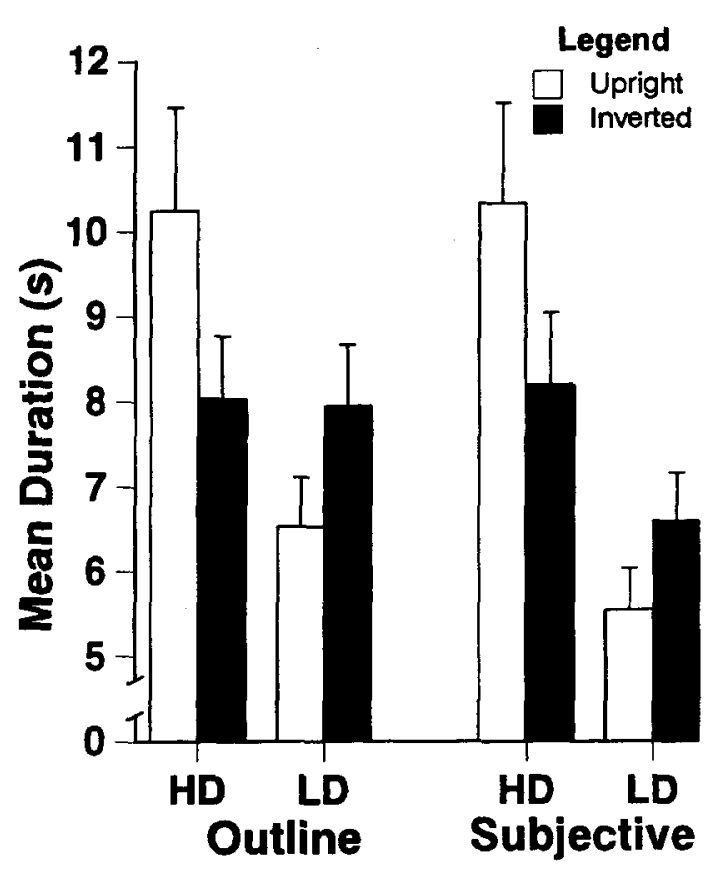

Figure 6. The mean durations of seeing intended high and low denotative regions as figure as a function of orientation for the two types of stimuli used in Experiment 2. Outline stimuli are shown on the left (real contour stimuli); subjective contour stimuli, on the right. HD, high denotative region; $L D$, low denotative region. The upright condition is represented by white bars; the inverted condition, by black bars. 
$[F(1,31)=4.51, p<.05]$ : Low denotative regions were maintained as figure for longer durations in outline contour stimuli $(7.24 \mathrm{sec})$ than in subjective contour stimuli $(6.07 \mathrm{sec})$, whereas high denotative regions were maintained as figure for approximately equal durations in outline $(9.14 \mathrm{sec})$ and subjective $(9.26 \mathrm{sec})$ contour stimuli. Again, the three-way interaction among denotivity, stimulus type, and orientation failed to reach significance $(F<1)$, suggesting that the presence of shape recognition inputs to figure-ground organization does not depend on the presence of a real, as opposed to a subjective, contour. Therefore, we do not take the two-way interaction between denotivity and stimulus type to indicate that prefigural shape recognition processes operate differently on subjective and outline contours. As in Experiment 1, we ascribe this effect to an orientationindependent factor-the peripheral perceptibility of the contour, which was apparently relevant to discerning the low denotative regions but not the high denotative regions.

Intended regions were maintained as figure longer when subjects were fixating a point located inside that region $(9.80 \mathrm{sec})$ rather than a point located outside that region $(6.06 \mathrm{sec})$, as is indicated by a main effect of fixation location $[F(1,31)=23.59, p<.0001]$. This finding replicates the fixation location effect obtained in Experiment 1. No two- or three-way interactions involving fixation location were significant (all $p \mathrm{~s}>.09$ ). Again, fixation location influences on figure-ground organization appear to be separate from the shape recognition influences.

The height of the bars on the two regions of the figureground stimulus exerted no influence on figure-ground organization $(p>.10)$.

Durations of maintaining unintended regions as figure $(\boldsymbol{U})$. The patterns evident in the unintended responses were similar to those evident in the intended responses. Unintended high denotative regions were seen as figure for longer durations when the stimuli were upright rather than inverted. On the other hand, unintended low denotative regions were seen as figure for shorter durations when the stimuli were upright rather than inverted, indicating shorter latencies to obtain the (intended) high denotative regions by reversal out of seeing unintended low denotative regions as figure for upright stimuli rather than in inverted stimuli. An ANOVA conducted on the $U$ measures revealed a main effect of denotivity $[F(1,31)=8.20, p<.008]$ and a two-way interaction between denotivity and orientation $[F(1,31)=4.84, p<.04]$. These orientation-dependent denotivity effects were obtained for both types of stimuli: neither the main effect of stimulus type $(p>.66)$ nor any two- or three-way interactions involving stimulus type were significant (all $p s>.20$ ). The unintended durations showed a significant main effect of fixation location: Fixated unintended regions were maintained as figure longer than nonfixated unintended regions (5.53 vs. $3.58 \mathrm{sec}$ ). Thus, in Experiment 2, as in Experiment 1, both orientation-dependent denotivity effects and fixation location effects were evident in both the $I$ and the $U$ durations, indicating that these factors exert an influence on figure-ground organization that is independent of the viewers' intentions. The main effect of line height failed to reach significance in the unintended durations $(p>$ .15 ), as did any interactions involving line height (all $p \mathrm{~s}>.08$ ).

Thus, the results obtained with the subjective contour stimulus replicated the patterns obtained with the stimuli used in Experiment 1. High denotative regions were both more likely to be obtained as figure and more likely to be maintained as figure when the stimuli were upright rather than inverted. Subjective contours supported the operation of prefigural recognition processes just as real contours did, which was expected, given the evidence that subjective contours are constructed early in visual processing (e.g., Gurnsey et al., 1992; Peterhans \& von der Heydt, 1989).

\section{GENERAL DISCUSSION}

In two experiments, for three types of figure-ground contours, we found that high denotative regions were both obtained as figure faster and maintained as figure longer when the stimuli were upright rather than inverted. This is the pattern of results we take to indicate the operation of prefigural recognition processes. Thus, these experiments suggest that luminance edges, outline drawings, and subjective contours serve as approximately comparable substrates for the operation of prefigural recognition processes. This is not to say that all contours provide equivalent substrates for prefigural recognition processes. We have found that prefigural recognition processes can operate on the edges of 3-D stimuli only when the edges are defined by a luminance difference as well as by binocular disparity, but not when they are defined by binocular disparity alone (Peterson \& Gibson, 1993). Edges that are available only after stereo fusion is completed are not available early enough in processing to support the operation of recognition processes that influence either figure-ground reversal or initial figure-ground organization.

The results reported here were obtained in a reversal paradigm in which viewers were aware of the potential alternative interpretations. Not all theoreticians accept the premise that reversals obtained under such conditions can provide evidence about normal perceptual processes occurring in the absence of prior knowledge about what will be seen. For example, Rock and his colleagues (Girgus, Rock, \& Egatz, 1977; Rock \& Mitchener, 1992) have shown that naive observers may be less likely to report reversals of certain ambiguous stimuli than observers who have been informed of the potential alternatives. With respect to our data, we point out that the orientation dependence of our results demonstrates that our phenomena are not dependent on semantic knowledge. Knowledge regarding which shape was depicted by the high denotative region was insufficient to produce shape recognition contributions to figureground organization in the absence of an orientationdependent match to a representation of an object in mem- 
ory (e.g., in the inverted condition). This finding indicates that our results require access to a memory representation specifying the canonical orientation of a shape before the completion of figure-ground organization; motivation or knowledge is not sufficient. Furthermore, we have obtained similar results when naive observers reported the first perceived figure-ground organization in a paradigm employing brief masked exposures (Gibson \& Peterson, 1994; Peterson \& Gibson, 1991b, in press). This is exactly what would be expected if our reversal data do indeed model initial organization.

In addition, the results of the two experiments reported here are consistent with the results of experiments done with 3-D stimuli (Peterson \& Gibson, 1993), center- surround stimuli (Peterson et al., 1991), and stimuli depicting bounded convex regions (Peterson \& Gibson, in press).

\section{Alternative Explanations}

Rather than accept the notion that prefigural recognition processes operate on both sides of contours before figure-ground organization is completed, some may prefer the view that alternations in figure-ground organization were entertained before conscious perception. This view, articulated by Epstein and DeShazo (1960) and by Rock (1975), and held implicitly by many theoreticians of perception, claims that prior to conscious perception, one region is chosen first as figure and then is matched to representations of objects in memory. If a sufficiently good match is not found, figure-ground organization reverses rapidly (and still unconsciously), and the region on the other side of the contour, now being the (unconscious) figure, is matched to representations in object memory. This preconscious oscillation theory retains the assumption that matches to shape representations can occur only after figure-ground organization has produced a figure, but it does so at the cost of relinquishing the assumption that the consciously perceived figure-ground organization is necessarily the first produced in the course of visual processing.

It will be difficult to distinguish the preconscious oscillation theory from our theory, partly because preconscious oscillations are difficult to observe and partly because the details of the preconscious oscillation theory have not been sufficiently elaborated. Published presentations of the theory have not stated whether or not the results of matches to shape representations are expected to dominate figure-ground organization, for example. (Other results of ours show that inputs from object recognition processes do not dominate figure-ground organization and depth segregation; Peterson \& Gibson, 1993, in press). Rather than attempt to infer testable consequences of the preconscious oscillation theory, we have tested predictions from our theory regarding which types of edges should support the operation of prefigural recognition processes. We have proposed that prefigural recognition processes require as a substrate contours or edges that can be detected early in visual processing. In the experiments reported here, we found approximately equiv- alent effects when using stimuli constructed from luminance edges, outline drawings, and subjective contours. We noted that Rock (1983) and others have explained subjective contours as arising late in processing, resulting from a preconscious organization and reorganization processes similar to that proposed for figure-ground organization in the preconscious oscillation theory. Our finding that subjective contours are approximately equivalent to real contours as substrates for prefigural recognition processes seems inconsistent with the view that the perception of subjective contours themselves arises from a process of preconscious organization and reorganization.

\section{Fixation Location}

The experiments reported here provided empirical evidence that fixation location is relevant to figure-ground organization. Both Hochberg (1971) and Sejnowski and Hinton (1987) have suggested that fixation location and/ or spatial attention location influence figure-ground organization. Until now, however, no empirical evidence has been offered in support of these conjectures. Our methods have shown that fixation location contributes to figure-ground organization regardless of the viewer's intentions (i.e., main effects of fixation location were evident in both the $I$ and the $U$ durations). In addition, our experiments suggest that the inputs to figure-ground organization from fixation location are separate from the inputs from prefigural shape recognition processes.

\section{REFERENCES}

Barrow, H. G., \& Tennenbaum, J. M. (1981). Interpreting line drawings as three-dimensional surfaces. Artificial Intelligence, 17, 75-116. BIEDERMAN, I. (1987). Recognition-by-components: A theory of human image understanding. Psychological Review, 94, 115-147.

Clowes, M. B. (1971). On seeing things. Artificial Intelligence, 2, 79-116.

CoRNWELl, H. G. (1964). Effect of training on figure-ground organization. Journal of Experimental Psychology, 68, 108-109.

DutTon, M. B., \& Traill, P. M. (1933). A repetition of Rubin's figureground experiment. British Journal of Psychology, 23, 389-400.

EHRENSTEIN, W. (1987). Modifications of the brightness phenomenon of L. Hermann (A. Hogg, Trans.). In S. Petry \& G. Meyer (Eds.), The perception of illusory contours (pp. 35-40). New York: Springer-Verlag. (Originally published in 1941 as Über Abwandlungen der L. Hermannschen Helligkeitserscheinung. Zeitschrift für Psychologie, 150, 83-91)

EPSTEIN, W., \& DeShazo, D. (1960). Recency as a function of perceptual oscillation. American Journal of Psychology, 74, 215-223.

Gibson, B. S., \& Peterson, M. A. (1994). Does orientation-independent object recognition precede orientation-dependent recognition? Evidence from a cuing paradigm. Journal of Experimental Psychology: Human Perception \& Performance, 20, 299-316.

GinSBURG, A. (1975). Is the illusory triangle physical or imaginary? Nature, 257, 219-220.

Girgus, J. J., Rock, I., \& Egatz, R. (1977). The effect of knowledge of reversibility on the reversibility of ambiguous figures. Perception \& Psychophysics, 22, 550-556.

GotTsChaL.DT, K. (1929). Gestalt factors and repetition. In W. D. Ellis (Ed.), A source book of Gestalt psychology (pp. 109-135). London: Kegen Paul, Trench, Trubner.

GrossberG, S., \& Mingolla, E. (1985). Neural dynamics of perceptual grouping: Textures, boundaries, and emergent segmentations. Perception \& Psychophysics, 38, 141-171.

Gurnsey, R., Humphrey, G. K., \& Kapitan, P. (1992). Parallel dis- 
crimination of subjective contours defined by offset gratings. Perception \& Psychophysics, 52, 263-276.

Halverson, J. (1992). The first pictures: Perceptual foundations of Paleolithic art. Perception, 21, 389-404.

HeBв, D. O. (1949). The organization of behavior. New York: Wiley.

Hochberg, J. (1968). Perception. Englewood Cliffs, NJ: PrenticeHall.

Hochberg, J. (1971). Perception I: Color and shape. In J. W. Kling and L. A. Riggs (Eds.), Woodworth and Schlossberg's Experimental psychology (3rd ed., pp. 395-474). New York: Holt, Rinehart \& Winston.

HochBERG, J. (1972). The representation of things and people. In E. H. Gombrich, J. Hochberg, \& M. Black (Eds.), Art, perception, and reality (pp. 47-94). Baltimore, MD: Johns Hopkins University Press.

HochBerg, J. (1978). Art and perception. In E. C. Carterette \& M. P. Friedman (Eds.), Handbook of perception: Vol. X. Perceptual ecology (pp. 223-258). New York: Academic Press.

HoChBerG, J., \& Peterson, M. A. (1987). Piecemeal organization and cognitive components in object perception: Perceptually coupled responses to moving objects. Journal of Experimental Psychology: General, 116, 370-380.

Hochberg, J., \& Peterson, M. A. (1993). Mental representations of occluded objects: Sequential disclosure and intentional construal. Giornale Italiano di Psicologia, 20, 805-820.

Hoffman, D. D., \& Richards, W. A. (1985). Parts of recognition. In S. Pinker (Ed.), Visual cognition (pp. 65-96). Cambridge, MA: MIT Press.

Jenkins, B., \& Ross, J. (1977). McCullough effect depends on perceived organization. Perception, 6, 399-400.

Jolicoeur, P. (1985). The time to name disoriented objects. Memory \& Cognition, 13, 289-303.

Jolicoeur, P. (1988). Mental rotation and the identification of disoriented objects. Canadian Journal of Psychology, 42, 461-478.

KanIzSA, G. (1976). Subjective contours. Scientific American, 235(4), 48-52.

Kanizsa, G. (1979). Organization in vision. New York: Praeger.

KenNEDY, J. M. (1974). A psychology of picture perception. San Francisco: Jossey-Bass.

KENNEDY, J. M. (1988). Line endings and subjective contours. Spatial Vision, 3, 151-158.

KENNEDY, J. M., \& SILvER, J. (1974). The surrogate functions of lines in visual perception: Evidence from antipodal rock and cave artwork sources. Perception, 3, 313-322.

KossLYN, S. M. (1987). Seeing and imagining in the cerebral hemispheres: A computational approach. Psychological Review, 94, 148-175.

Lowe, D. (1985). Perceptual organization and visual recognition. Boston: Kluwer.

MARR, D. (1982). Vision. San Francisco: W. H. Freeman.

Marr, D., \& Hildreth, E. (1980). Theory of edge detection. Proceedings of the Royal Society of London: Series B, 207, 187-217.

MARR, D., \& NishIHARA, H. K. (1978). Representation and recognition of the spatial organization of three-dimensional shapes. Proceedings of the Royal Society of London: Series B, 200, 269-294.

McClelland, J. L., \& Rumelhart, D. E. (1981). An interactive activation model of context effects in letter perception: Part 1. An account of the basic findings. Psychological Review, 88, 375-407.

Nakayama, K., Shimojo, S., \& Silverman, G. H. (1989). Stereoscopic depth: Its relation to image segmentation, grouping, and the recognition of occluded objects. Perception, 18, 55-68.

Paradiso, M. A., Shimojo, S., \& Nakayama, K. (1989). Subjective contours, tilt aftereffects, and visual cortical organization. Vision Research, 29, 1205-1213.

Pastore, N. (1971). Selective history of theories of visual perception, 1650-1950. New York: Oxford University Press.

Peterhans, E, \& von der Heydt, R. (1989). Mechanisms of contour perception in monkey visual cortex: II. Contours bridging gaps. Journal of Neuroscience, 9, 1749-1763

Peterson, M. A. (1986). Illusory concomitant motion in ambiguous stereograms: Evidence for nonstimulus contributions to perceptual organization. Journal of Experimental Psychology: Human Perception \& Performance, 12, 50-60.

Peterson, M. A. (1994). Object recognition processes can and do op- erate before figure-ground organization. Current Directions in Psychological Science, 3, 105-111.

Peterson, M. A., \& Gibson, B. S. (1991a). Directing spatial attention within an object: Altering the functional equivalence of structural descriptions. Journal of Experimental Psychology: Human Perception \& Performance, 17, 170-182.

Peterson, M. A., \& Gibson, B. S. (1991b). The initial identification of figure-ground relationships: Contributions from shape recognition processes. Bulletin of the Psychonomic Society, 29, 199-202.

Peterson, M. A., \& Gibson, B. S. (1993). Shape recognition contributions to figure-ground organization in three-dimensional displays. Cognitive Psychology, 25, 383-429.

Peterson, M. A., \& Gibson, B. S. (in press). Must figure-ground organization precede shape recognition? An assumption in peril. Psychological Science.

Peterson, M. A., Harvey, E. M., \& Weidenbacher, H. J. (1991). Shape recognition contributions to figure-ground reversal: Which route counts? Journal of Experimental Psychology: Human Perception \& Performance, 17, 1075-1089.

Peterson, M. A., \& Hochberg, J. (1983). Opposed-set measurement procedure: A quantitative analysis of the role of local cues and intention in form perception. Journal of Experimental Psychology: Human Perception \& Performance, 9, 183-193.

Peterson, M. A., \& Hochberg, J. (1989). Necessary considerations for a theory of form perception: A theoretical and empirical reply to Boselie and Leeuwenberg (1986). Perception, 18, 105-119.

Petry, S., Harbeck, A., Conway, J., \& Levey, J. (1983). Stimulus determinants of brightness and distinctness of subjective contours. Perception \& Psychophysics, 34, 169-174.

REYNOLDS, R. I. (1981). Perception of an illusory contour as a function of processing time. Perception, 10, 107-115.

Rock, I. (1962). A neglected aspect of the problem of recall: The Hoffding function. In J. M. Scher (Ed.), Theories of the mind. New York: Free Press of Glencoe.

Rock, I. (1975). An introduction to perception. New York: MacMillan.

Rock, I. (1983). The logic of perception. Cambridge, MA: MIT Press, Bradford Books.

Rock, I., \& ANSON, R. (1979). Illusory contours as the solution to a problem. Perception, 8, 665-681.

Rock, I., \& DiVITA, J. (1987). A case of viewer-centered object perception. Cognitive Psychology, 19, 280-293.

ROCK, I., \& FLECK, F. (1950). A re-examination of the effects of monetary reward and punishment on figure-ground perception. Journal of Experimental Psychology, 40, 766-776.

ROCK, I., \& KREMEN, I. (1957). A re-examination of Rubin's figural aftereffect. Journal of Experimental Psychology, 53, 23-30.

RoCK, I., \& MitCHENER, K. (1992). Further evidence of failure of reversal of ambiguous figures by uninformed subjects. Perception, $\mathbf{2 1}$, 39-45.

RUBIN, E. (1958). Figure and ground. In D. C. Beardslee \& M. Wertheimer (Eds. \& Trans.), Readings in perception (pp. 194-203). New York Van Nostrand. (Original work published 1915)

SCHAFER, R., \& MURPHY, G. (1943). The role of autism in a visual figure-ground relationship. Journal of Experimental Psychology, 32, 335-343.

Schumann, F. (1987). Contributions to the analysis of visual perception-first paper: Some observations on the combination of visual impressions into units (A. Hogg, Trans.). In S. Petry \& G. Meyer (Eds.), The perception of illusory contours (pp. 21-34). New York: Springer-Verlag. (Original work published 1900)

SEJNOWSKI, T. J., \& HinTon, G. E. (1987). Separating figure from ground with a Boltzman machine. In M. Arbib \& D. Hanson (Eds.), Vision, brain and cooperative computation (pp. 703-724). Cambridge, MA: MIT Press.

SMiTH, A., \& OVER, R. (1975). Tilt aftereffects with subjective contours. Nature, 257, 581-582.

SMiTH, D., \& HochBERG, J. (1954). The effects of "punishment" (electric shock) on figure-ground perception. Journal of Psychology, 37 , 83-87.

TARR, M. J., \& PINKER, S. (1989). Mental rotation and orientationdependence in shape recognition. Cognitive Psychology, 21, 233-282. von der HeydT, R., \& Peterhans, E. (1989). Mechanisms of contour 
perception in monkey visual cortex: I. Lines of pattern discontinuity. Journal of Neuroscience, 9, 1731-1748.

von der Heydt, R., Peterhans, E., \& Baumgartner, G. (1984). Illusory contours and cortical neuron responses. Science, 224, 1260-1262.

WALLACH, H. (1949). Some considerations concerning the relationship between perception and cognition. Journal of Personality, 18, 6-13.

\section{NOTES}

1. From here on in, we use the terms shape recognition and shape memory because we are dealing with two-dimensional (2-D) figures. Nevertheless, we expect that the recognition processes and representations are the same for 3-D objects (see Halverson, 1992; Hochberg, 1972; Kennedy \& Silver, 1974).

2. We use a continuum of denotivity rather than familiarity because the effects of laboratory induced familiarity appear to be labile. We do not use the term meaningful, because that term has implications regarding connotivity, and connotivity per se is not relevant to our effects (see Peterson \& Gibson, 1993, for further discussion).

3. No more than $10 \%$ of the observers in the preliminary study agreed on a single interpretation for the low denotative regions of inverted stimuli; and no more than $13 \%$ agreed on a single interpretation for the high denotative regions of inverted stimuli.

4. Note that our proposal that some shape recognition processes are conducted prefigurally does not entail that the entire shape recognition process is completed prior to figure-ground computations, nor does it exclude the possibility that other shape recognition processes operate after figure-ground computations are completed.
5. The use of stimuli in which only the central contour carries shape recognition information eliminates the possibility that observers might attend differentially to contours other than the experimental contour. (This is not to say that the implied occlusion at the outer borders is unimportant; pilot observers were less likely to agree about which object was depicted by the high denotative regions when the top, bottom, and outer borders were not clearly occlusion borders.)

6 . The fixation point is present only on the region that observers were instructed to fixate. We have replicated some of the effects reported here by using stimuli containing a fixation point on both regions, and by manipulating location of fixation by instruction alone. Thus, any effects of fixation location should not be attributed to the presence of extra detail on the intended region.

7. The organization perceived for 2-D stimuli often satisfies the joint criteria mentioned at the beginning of this Procedure section (Rubin, 1915/1958; Halverson, 1992), although it is not necessarily the solution (Kennedy, 1974; Rubin, 1915/1958). Nevertheless, we gave observers in our experiment the option to remove $\beta$ their fingers from both response keys to indicate that the display appeared flat like a mosaic or that the shapes depicted by both regions could be seen simultaneously. Observers used this response option very rarely $(M \mathrm{~s}=$ $1.17 \mathrm{sec}$ in Experiment 1 and $.82 \mathrm{sec}$ in Experiment 2), as would be expected if indeed there exists a tendency for the figure both to have a definite shape and to appear to occlude the background.

(Manuscript received March 22, 1993; revision accepted for publication May 18, 1994.) 